\title{
Disease-Free Survival
}

National Cancer Institute

\section{Source}

National Cancer Institute. Disease-Free Survival. NCI Thesaurus. Code C17751.

The length of time after treatment for a specific disease during which a patient survives with no sign of recurrence of the disease. 